\title{
Lo peor ya ocurrió
}

\section{SANTIAGO KOVADLOFF}

Hay, al parecer, una turbulencia propia de los fines de milenio. Quienes nos precedieron, hace diez siglos, la conocieron bien. Lo prueba una literatura febril y abigarrada, que se remonta por lo menos hasta los Oráculos sibilinos recopilados en el siglo VI, y culmina con la versión francesa de la Tiburtina, en el siglo XI. Su rasgo prototípico es el presentimiento de una catástrofe universal inminente y de consecuencias irreparables. De modo que si la expresión "fin del mundo" pareciera caída en desuso, no ocurre lo mismo con su trágico sentido. Se diría que todo milenio exhausto arrastra siempre, entre sus aguas terminales, el temor a lo peor. De hecho, basta una ojeada a cuanto nos rodea para advertir que la violencia suele cambiar de promotores y banderas pero no de intensidad. Se diría que el desastre se niega a conocer matices y así es cómo, en su magnitud sin mengua, tiende a devorarlo todo: desde el trato entre los pueblos hasta el vapuleado tejido de la atmósfera, haciendo resaltar con ello una arraigada indiferencia hacia el don convivencial.

Aún así vale la pena indagar si lo peor va a ocurrir o ya ocurrió. Mi impresión es que ninguna de las tragedias venideras, resulten o no inminentes, será más desoladora que las que ya padecimos -Auschwitz, por ejemplo, e Hiroshima-. Acaso lleguen ellas a igualarlas. Pero no creo que puedan superarlas "cualitativamente". Es que, a mi ver, de cuantos males pudiera entrañar el futuro, no hay ninguno capaz de sorprendernos (aunque sí de espantarnos) con la hondura de su embestida o la magnitud de su crueldad.

Se me dirá de inmediato que la hecatombe nuclear que ponga fin a la vida entre nosotros no tuvo lugar todavía. ¿ Debo aclarar que lo sé ? Cabe reconocer, no obstante, que semejante atrocidad no es, estrictamente, lo peor que podría suceder. Y no lo es por una razón que salta a la vista: no habrá quien sobreviva al desastre como para tener que soportar sus consecuencias. Va de suyo que el fin del mundo es también el fin del padecimiento humano. No habrá calvario donde ya no existan protagonistas del dolor. Ni puede imperar el horror donde no haya sobrevivientes en condiciones de absorberlo. De modo que si nadie subsistirá a la siembra radical del mal ya no estaremos ante lo peor. Estaremos-si es que de estar se trata-inmersos en la nada o, más exactamente, disueltos en ella, aniquilados.

No pareciera pues que lo peor, en un sentido eminente, vaya a suceder sino que ya sucedió. Lo peor -vivencia y conciencia del extremo horror consumado- no nos aguarda, nos precede. No se insinúa en el horizonte, donde sí puede, siempre, anidar el mal. La huella de lo peor se dibuja hoy detrás de nosotros y allí debe ser buscada y reconocida. Esa huella es la del genocidio sistemático, la de su producción industrial. Esa huella es también la de la hecatombe nuclear programada.

El genocidio sistemático ya tuvo lugar. Allí están, todavía, los hornos crematorios, la desolada extensión de los campos de exterminio. Hay en Tel Aviv una pared ineludible donde consta el nombre de cada uno de los judíos inmolados. Hiroshima y Nagasaki no son males venideros. No debe temerse, entonces, el advenimiento de lo peor. Lo peor ya pasó. Es un contrasentido aguardar, como novedoso, lo ya sucedido. No vamos hacia lo atroz sino que 
provenimos de lo atroz, concebido como lo imposible de ser radicalizado. Somos, en esa medida, sobrevivientes. Estamos, como tales, y en el más extremo de los casos, expuestos a la posibilidad de volver a pasar por las mismas y pavorosas experiencias, acaso cuantitativamente agravadas. Pero, como he dicho, ya no podremos ingresar a un horror inédito, pues éste ha sido consumado. Hemos transpuesto el umbral de lo mensurable; la frontera que nos separaba de lo incalificable. El tristemente célebre "día después" es nuestro presente. Él nos impone, en consecuencia, una pregunta: la que incita a saber si el hombre es aún posible.

El sobreviviente de lo peor lleva estampado en su frente el estigma de su origen. Lo ha dado a luz la desmesura brutal. El desprecio por toda alteridad. La subestimación de todo lo que no es él mismo y aun de lo que esencialmente es él mismo. Como tal, es fruto del menoscabo del valor de la diferencia. De la repulsión por todo lo que no es idéntico. Por todo lo que no es reflejo servil de su presunta mismidad.

Ese hombre sin matices es hijo de una subestimación primordial: la de la conciencia que ya no se entiende a sí misma como respetuosa de una dimensión trascendente de lo real; la de la conciencia que ya no se siente relacionada con esa trascendencia irreductible a las formas del saber y la política, y que pugna, pese a todo, por ser reconocida como misterio que a esa conciencia le es pertinente. Lo trascendente es lo que se sitúa más allá de toda norma pero en íntima relación con ella; lo que está fuera de la ley y atañe no obstante a la ley, lo anómalo por excelencia y, aún así pertinente a la normalidad y a lo normativo. Trascendente es lo que se resiste a la manipulación y la denuncia, a la inscripción y la desbarata, a la imaginación y la convoca.

Pero también, ese hombre sin matices llega a ser hijo del cansancio y aún de la angustia ante la devastación sembrada por tanta soberbia. Es decir que si efectivamente lograra sobrevivir a su pasado será porque no ha sido atrapado para siempre en semejante subestimación. Si se sobrepusiera a sí mismo ha de ser porque ha sabido dejarla atrás. Pero atrás no significa sumida en el olvido ni tampoco inscripta en una memoria meramente evocativa. Se trata, en fin, de saber si el porvenir de ese hombre es, predominantemente, el de la repetición de lo sucedido. Para innovar y no seguir donde está, debe reconstruir de algún modo su sentimiento de relación con la verdad de aquella trascendencia sumida ahora en lo irrelevante. Ese hombre debe reubicarse, abrirse, reintegrarse. Y ello significa restituirle dignidad y valor orientador al padecimiento del que proviene, comprender la función orquestal a que está llamada la auténtica individualidad. Hoy ese padecimiento está menoscavado. Como si la hondura del dolor nada tuviese para enseñarnos. En parte ello es así a consecuencia del triunfalismo del cual son expresión la opulencia y el consumo sin freno. En parte, también, debido al embrutecimiento impuesto por la miseria y la desesperación a quienes son cada vez más y significan cada vez menos.

Aquel triunfalismo y esta miseria son vertientes de una misma renegación. $\mathrm{La}$ renegación del fracaso. La renegación de la verdad iluminada por un quebranto sin igual del valor y las exigencias de unidad de la especie y de su interdependencia con las demás formas de la vida. Renegación de lo peor que es, en última instancia, la catástrofe que ya tuvo lugar pero que no ha sido asumida como lo ya sucedido, sino tergiversada en una formulación retórica que pretende, perversamente, que lo peor todavía podría llegar a suceder y que, en consecuencia, habría que prevenirlo.

Esta renegación cabe, en suma, en un nombre y ese nombre es el del egoísmo. $\mathrm{Su}$ vigencia resulta de la supremacía de 
un ideal. Ese ideal propone que el hombre es una presencia aislada en la cima de la existencia. Nada ni nadie le exige subordinarse a ninguna otra ley que no sea la que dicta su voluntad, la que imponen sus sueños o su deseo. Ese ideal aspira a entronizar como indiscutible la suposición de que el hombre es autónomo, un ser incondicionado que puede hacer de sí y del mundo lo que le plazca. Ese ideal se burla de la vida inconsciente, de las imposiciones de la muerte y del enigma del origen de la vida espiritual, como si se tratara de barreras impuestas por un adversario o un competidor y a las que no corresponde sino apartar con desdén y suficiencia.

El fundamento del egoísmo se afianza sobre una decisión: la de repudiar y poner fin a esa doble imposición ontológica según la cual el hombre no sólo es quien es en referencia a un inagotable llamado a trascenderse sino, además, a trascenderse incesantemente en el perfeccionamiento de su solidaridad social, pues ella es la expresión ética por excelencia de su misterio; de ese íntimo desvelo que hace de él un ser que consiste en buscarse en el vínculo con el otro.

El egoísmo se consolida cuando el hombre abdica de sí como criatura. Cuando impugna la idea de la creación humana como acto que, sin dejar de ser suyo, de estar asentado en una decisión, está a la vez facultado, o sea que es una posibilidad con la que el hombre cuenta. El egoísmo induce a concebir como enteramente incondicionadas la invención humana y la autodeterminación humana, como si ellas nada dijesen de él como ser habilitado por un don sobre cuya realidad nada sabe y todo lo presume. En consecuencia, el egoísmo aspira a entender y a hacer entender al hombre como aquél que exige acatamiento por parte de todo lo que no es él y por parte de todos los que no son como él, aunque se pretendan humanos. El del egoísmo es el reino de la particu- laridad desasida de toda interdependencia. El desenfrenado imperio del Único. De tal modo, el auto- producirse se afianza como patrón excluyente de medida y, con él, el producir entendido como el proceder característico del amo. Así, el universo, conjunción milagrosa, en la conciencia, de lo concebible y lo inconcebible, de lo mensurable y lo inconmensurable, se empequeñece en ese hombre hasta ganar la falsa transparencia de lo doméstico, haciendo de lo incondicionado un sitio, una cifra, una etiqueta y donde lo que irreductiblemente se ignora se ve reducido a lo que momentáneamente no se sabe o rebajado a lo que poco o nada importa

Si el hombre se aparta del espíritu de comunión no podrá reconocerse como criatura. No se verá, si así procede, como expresión simultánea de una identidad que lo busca y de un enigma que lo interpela convocándolo a la convivencia. Tampoco verá, en las demás expresiones de esa realidad -de ese todo intotalizable-, ninguna manifestación de su propia médula. Para él no habrá sino fragmentos ajenos entre sí, dispersos, hostiles unos a otros, terca autonomía de un yo también segmentado. Aisladas, repartidas, disgregadas, las múltiples formas -que sólo en relación con lo real admitido y sostenido como lo en última instancia indecible alcanzan un significado parental para el espíritu- terminan reduciéndose, en su percepción enajenada, a la condición de cosas, trozos, bienes, cifras. Como tales, no despiertan, en su sensibilidad, más que afán posesivo o clasificatorio, curiosidad, hostilidad o indiferencia. Y habrá entonces que ordenarlas, forzarlas a rendir, terminar con ellas o ignorarlas- que es lo mismo.

Sobre este suelo de incesantes disociaciones se pudo preparar el cumplimiento del genocidio sistemático y de la hecatombe nuclear programada. Es en él donde se gestó lo peor y su advenimiento. El centro de la tragedia radica, pues, en el paté- 
tico desprecio por lo que la identidad llamada propia tiene de impropia e inapropiable. Pero lo impropio y lo inapropiable, lo imponderable en suma, no se deja malbaratar servilmente y reacciona. Reacciona y retorna. Presiona y retorna. Sorprende, puja y retorna.

En un sentido político, se ha producido lo que Víctor Massuh ha llamado "la tumultuosa explosión de las particularidades humanas". Hay una singularidad que resulta insoluble en lo genérico universal y ella insiste, sin mengua, en reivindicar su concreción y su derecho. Y lo hace contra el falso universalismo de esa "pasión revolucionaria" que, según, Massuh, "abusó del futuro y nos intoxicó de utopías, sociedad marxista, evidencia redentora, hombre nuevo, mañanas que cantan, paraísos tecnológicos, reino del hombre desalienado". Prueba de ello son las minorías que hoy batallan por el reconocimiento de su especificidad como algo irrenunciable. Todo esto en un mundo que conduce, a su vez, hacia una globalización que, cuando está mal encarada impulsa hacia la disolución forzosa de lo singular en lo general. He aquí el riesgo que asecha al sobreviviente: verse anonadado. Ser inventariado como nadie.

La condición humana implica, en lo fundamental, ser en la forma de lo abierto a lo desemejante, a cuanto rebasa, en nosotros y fuera de nosotros, la mismidad. La posibilidad del amor se constituye mediante el trato cordial con esa heteronomía. Con eso que se resiste a la demanda imperativa de unidad, a la ilusión empecinada de ser uno, en la medida en que resulta irreductible a toda forma familiar y que no obstante brinda, a cada uno de nosotros, la posibilidad de que nos reconozcamos básica, auténtica y dolorosamente. Porque el amor es goce y padecimiento de la diferencia irreductible. Y no sólo ni en primer término de la diferencia que hay entre uno y otro, sino, ante todo, de la diferencia que hay entre lo abordable y lo inabordable de cada cual para cada cual. Ser, para el hombre, es no poder conformarse; imponerse ante su propia conciencia vigilante como otro que él mismo. Esbozo, aproximación, dilema. En verdad, lo humano del hombre sólo aflora a partir del contacto con lo extraño de sí, en el autodesconocimiento que lo desvela y lo confirma como existente. La disonancia lo delata y lo confirma. Es su propia anomalía la que le habla al hombre de sí como criatura y ya no -digámoslo otra vez- de sí como uno mismo. Como criatura el hombre es un ofrendado a la vida; el ser incorporado a lo real como tiempo, mediante leyes extrañas y más radicales que las dictadas por su voluntad. Así entendido, el hombre es alguien que ha sido conformado, impuesto, provisto, y no únicamente ni primeramente un proveedor. Concomitante del homo faber es el homo factum. El habilitante es, al unísono, el habilitado. Esta simultaneidad del factum con el faber es, por supuesto, temporal. Ambos atributos se revelan al unísono. Lo primordial que faculta se deja ver en la acción que posibilita y resulta indisociable de ella, aunque no por eso homologable a ella. Es la aptitud, la virtud que se da a conocer en su despliegue instrumental a quien esté dispuesto a advertirla.

El logro siempre insuficiente de su humanidad exige del hombre que supere constantemente la comprensión unidimensional de su ser. No otra cosa implica el reconocimiento y la asunción de la heteronomía. Ésta, antes que una imposición moral en relación con los demás, es una exigencia constitutiva de su conciencia cuando está abocada a lo Abierto. El hombre puede atenderla o desatenderla. Pero ella le es dictada por la necesidad de ser humano. Al desapropiarse incesantemente de sí, el hombre queda a disposición del encuentro con lo desemejante. En condiciones de acceder al otro como prójimo y a sí como otro. 
Este acto infinito de desapropiación señala la inscripción creadora del hombre en el vínculo con el sufrimiento. En ella, el hombre se manifiesta como sobreviviente. Y sobreviviente quiere decir: situado, por fin, ante lo inalcanzable para sus propias manos, pero en íntima y laboriosa relación con cuanto lo inalcanzable implica. Es que sólo donde el espejismo de la posesión queda al descubierto puede haber lugar para el hombre como ser dialógico. $\mathrm{Y}$ es de tal modo, y únicamente de tal modo, que el hombre trasciende; es decir, ingresa al intercambio con el enigma de su propia presencia como aquél que queda a disposición creadora de ese enigma que hace de él otro que el mero dueño de un saber.

Es aquí, en este momento, cuando una de las grandes demandas bíblicas viene a interpelarnos una vez más. Es en su extraordinaria propuesta donde el sobreviviente de lo peor puede llegar a discernir un camino transitable.

Solemos malentender, lo cual indica también que nos cuesta soportar, el sentido radical que, en esa demanda, toma el amor a uno mismo. La demanda convoca a cada cual para que ame a su prójimo como a sí mismo. ¿Se me quiere decir con ello que debo llegar a amarlo tal como me amo? No. No así. Lo que sí se me quiere decir es que me empeñe en amarlo tal como podría llegar a amarme. Amarás a tu prójimo cuando efectivamente puedas amarte. No antes ni tampoco después. No de otro modo ni en otras circunstancias, sino allí y así: cuando puedas amarte. En ese instante y de ese modo. Reconocerás a tu prójimo al reconocerte como prójimo. No mientras te concibas como ahora te concibes, pues así nunca accederás a él. Es que tal como hoy concibes y practicas el amor a ti mismo, estás muy lejos de amarte cabalmente. En verdad, amándote como te amas, te desprecias. Vives de espaldas a lo más íntimo de ti; a eso que no es tuyo y no obstante te identifica. Te desconoces, por eso, tanto como desconoces a tu prójimo al darte a ti mismo por sabido y discernible en un saber acerca de cuya insuficiencia nada sospechas. Y por eso es que, ignorándote como te ignoras, te tributas el mismo maltrato que descargas sobre él.

El imperativo amarás remite al futuro. Impone una tarea. No exige la mera traslación a otro de algo ya consumado en uno; de algo que yo ya me brindo. La demanda amorosa invalida toda sucesión entre el tener y el brindar. Exige, en cambio, simultaneidad: presencia, presente. Que yo sea capaz de darme lo que sólo entonces, y al unísono, estaré dando. Lo amaré tal como me amaré. Me descubriré y entonces, en ese instante eminente, lo descubriré. No es un paso tras otro lo que cabe dar, sino un paso en el otro. El amor respira en la coincidencia. Respira en la comunión. Es caridad. En el fulgor de la simultaneidad; en el fervor de la convergencia realizada entre lo más cercano y lo más distante. El amor es el triunfo de la dualidad sobre la unidad; la puesta al descubierto del más íntimo secreto del uno que es ser dos.

Reconozco al otro, a mi prójimo, en el momento en que ya no puedo seguir ignorándome a mí mismo como alguien disonante con relación a ese hombre exclusivo y homogéneo que hasta allí he creído ser para mí. Hasta allí mis días sólo han sido gobernados por el protagonismo del Único, el ideal de lo Propio, la ilusión de lo Idéntico. Es decir que la demanda bíblica evidencia, además, mediante la intensidad con que formula su llamado, que a la hora de hacerse oír el amor brilla por su ausencia. Es recién a partir de la emisión de la demanda que el amor, como revolucionaria labor de caridad, se hace evidente como lo aún incumplido. El imperativo Amarás en tanto dice: tendrás al otro en cuenta, expresa, a la vez, aún no te amas o sea: no te has tomado en cuenta todavía. 
¿Pero si la demanda bíblica incita a amar, no incurre con ello en un contrasentido? ¿Puede la caridad ser una imposición, conformarse como exigencia? ¿Cómo puede el sentimiento amoroso emanar de una orden? ¿Es acaso factible decretar su irrupción, instaurar su práctica mediante un doble gesto de autoridad y sumisión? El imperativo Amarás, sin embargo, no responde a la suposición de que el sentimiento amoroso pueda ser impuesto. Responde, sí, a la determinación de impedir que se lo confunda con el egoísmo y se lo degrade en la mera autorreferencia. El imperativo amarás llama a la osadía de un sinceramiento. Convoca a la conciencia a un ejercicio de franqueza buberiana, es decir, de una puesta al desnudo del Yo en el Tú, del Tú reconocido por el Yo como aquello de sí que no se agota en la mismidad, que no cede al registro de lo idéntico vivido como lo homogéneo. Así como te amas -pareciera decirse- sólo hay lugar para el desprecio. Y el desprecio es siempre autodesprecio. Es egoísmo.

La demanda bíblica pide al hombre que despierte. Que se asome y se sostenga ante el paisaje que con esa demanda queda al descubierto. Ese paisaje tiene su centro en una evidencia que, en principio, sólo resulta conflictiva: uno no puede llegar a amarse si no se reconoce en disonancia consigo mismo, si no se separa de sí. Esta separación de sí como un todo autorreferente sobreviene con la admisión de otra presencia que la propia. Implica haber sabido acceder a cuanto revela mi alteridad, entendida como la de una criatura que se sabe como tal, es decir, impuesta, expuesta, habilitada por un enigma que las trasciende: el de la autoconciencia de sí como otro que aquél que se sabe, se conoce, se identifica.

La demanda bíblica me quiere develado en mi heteronomía. Ella me propone, además, aceptar esa heteronomía como núcleo vivencial de mi presencia asumida en el tiempo. Se trata, de modo eminente, de una reconciliación conmigo en tanto otro primordial. Ese otro al que remite siempre la palabra Yo y que, como tal, resulta irreductible a la exigencia de uniformidad que con frecuencia promuevo y reivindico al hablar de mí.

¿Qué significa aquí, entonces, reconciliación? Esto ante todo: íntima disposición al encuentro crítico con aquello que, en tanto objeto de posesión y de saber despótico, nos ha llevado, en última instancia, a la hecatombe nuclear y al genocidio. Así concebida, la reconciliación es acto de caridad -donación-y, al unísono, acto de presencia -un infinito tender hacia mí como otro; un infinito tender hacia el otro como expresión indisociable de mí. Construcción sin pausa, esfuerzo sin fin en dirección al llamado inextinguible que me formula mi inagotable alteridad. Llamado que es búsqueda y plegaria. Anhelo de ser oído que me demanda como oyente para ofrendarme la voz de cuanto en mí no es mío y, no obstante, también soy yo.

En esta aproximación caritativa a cuanto en mí no es mío, ni propio ni apropiable, ha de consistir el fundamento del amor al prójimo. En esa sed de alteridad que se realiza como encuentro de uno en otro, a medida que fracasa como posesión de uno por otro o -si se quiere- como reducción de uno a otro. Es que el amor, paradójicamente, se nutre y respira en la incesante impotencia para terminar de ser uno con el otro. Impotencia prodigiosa puesto que, en su reverso y al unísono, es don convivencial, aptitud para ser otro que uno gracias a él, allí donde ya no es posible ser uno sin él.

El amor permite que se conquiste, como iluminadora vivencia de identidad personal, la infinita distancia que a cada cual lo vincula consigo al separarlo de sí mismo. En ella consiste y allí reside lo humano por excelencia, mi prójimo, quien puedo ser. Mientras así no ocurra, no habrá seme- 
jantes para mí, ni yo seré celebrado como otro por nadie. El prójimo, en tal caso, será sólo mi reverso especular y maniqueo: si yo soy lo conocido, él será lo desconocido; si yo lo cercano, él lo distante, si yo soy quien poseo, él será quien no posee. Si yo lo soy todo, él será nada.

Recuerda Cicerón que el significado primario de la palabra "enemigo" ("hos- tis") fue "extranjero", el que proviene de afuera, de lo lejano e ignoto, el que habita la tierra según otro modo de ser. Aún palpita en nosotros ese antiguo horror a la diferencia. Pero también, y hoy más que nunca, la necesidad de rebasarlo. Esa necesidad que ha terminado por hacer de nosotros sobrevivientes. Esa necesidad que induce a pensar que lo peor ya ocurrió. 